\title{
Acceptability of Milk and Soymilk Vanilla Beverages. Demographics Consumption Frequency and Sensory Aspects
}

\author{
B. Villegas, I. Carbonell and E. Costell ${ }^{*}$
}

Physical and Sensory Properties Laboratory, Instituto de Agroquímica y Tecnología de Alimentos, CSIC. PO Box 73, 46100 Burjassot, Valencia, Spain

Acceptance of food is basically the result of the interaction between food and human and it depends not only on the product characteristics but also on those of each consumer. The main objective of this work is to analyse how the acceptability of milk and soymilk vanilla beverages is influenced by demographic characteristics, consumer habits and individual preferences and the sensorial properties of both products. Six commercial samples, comprising three milk beverages and three soymilk beverages of different brands and characteristics, were sensorially evaluated. Overall acceptability was tested by 142 consumers, using a 9-point hedonic scale and 36 assessors ranked the samples from the least to the most intense according to their yellow colour, brightness, vanilla flavour intensity, sweetness and thickness. The milk samples were significantly $(\mathrm{P}<0.05)$ more acceptable than the soymilk ones and were perceived as being stronger yellow and less light in colour, with a more intense sweetness, stronger vanilla flavour and thicker consistency. The results obtained lead us to the conclusion that the difference in acceptability between milk and soymilk beverages is more closely related to their sensorial attributes than to other characteristics (demographic, consumer habits and individual preferences) of the consumer population surveyed.

Key Words: vanilla beverages, soybean, milk, acceptability, consumers survey, consumer habits

\section{$<1>$ INTRODUCTION}

Soybean is an important protein source, a potential source of bioactive peptides and contains high levels of minerals and amino-acids (Hayta et al., 2003; Wang and de Mejía, 2005). Soymilk is one of the most popular soybean products, with plain and vanilla being the most common flavours, although these beverages are being developed in a wide variety of other flavours (Chambers et al., 2006). Soymilk and soymilk beverage consumption affords well-known health benefits (Hasler, 1998) and can also be an interesting alternative for consumers who are lactose intolerant, allergic to milk or avoid milk for any other reason (Reilly et al., 2006). The main problems facing the acceptance of soymilk and soymilk beverages is that their sensory characteristics do not match those of milk and

\footnotetext{
* To whom correspondence should be sent (e-mail: ecostell@iata.csic.es).

Received: 8 February 2008; revised: 9 May 2008.
} 
milk beverages, and that from the consumer's viewpoint, health is important but not at the expense of sensory quality (N'Kouka et al., 2004; Deshpande et al., 2005).

Some authors have described the presence of undesirable characteristics in the texture of these beverages, for instance chalky, dry or oily (N'Kouka et al., 2004; Deshpande et al., 2005; Potter et al., 2007). In spite of the importance of textural characteristics, the main factor limiting the consumption of soymilk products is related to their flavour, commonly being referred to as "beany", although more specific descriptions have been developed by sensory descriptive analyses of these products (TorresPeñaranda and Reitmeier, 2001; N'Kouka et al., 2004; Chambers et al., 2006). This beany flavour has been attributed to degradation products of polyunsaturated fatty acids induced by lipoxygenase enzyme (Keast and Lau, 2006). Consequently, one approach attempting to solve the flavour problem was to develop soy varieties with lower lipoxygenase content, in order to diminish the degree of fatty acid oxidation during the soymilk manufacturing process; however, results so far are not completely satisfactory (Yuan and Chang, 2007). Another approach to solve the undesirable flavour of soymilk involves trying to mask soy flavour by designing beverages with different flavourings, like vanilla, chocolate or almond flavour (Wang et al., 2001) or adding other ingredients. For instance, Deshpande et al. (2005) compared the sensory acceptability of chocolate-flavoured peanut-soy beverages with a commercial milkshake, obtaining beverages with significantly higher ratings for appearance, colour and sweetness, but not for overall liking when compared to the control. Also, Mepba et al. (2006) formulated coco-soy beverages, which were significantly less acceptable when compared to the milk control sample. Potter et al. (2007) formulated soy beverages containing wild blueberry and different soy protein ingredients to study which sensory attributes were related to overall acceptability of the product, and they found flavour attributes were the most closely related in the case of wild blueberrysoy acceptability.

Currently there are few or no data comparing the acceptability of commercial milk and soymilk beverages. It is clear that a consumer's final response is based on the perception of the different attributes that make up the sensorial quality of a product as a whole. Apart from the characteristics of food and the sensations that consumers can experience when ingesting it, the attitude and opinion of each consumer regarding the nutritional characteristics or the composition of the product, condition the consumers' choice when purchasing and may modify the degree of pleasure when consuming it (Barrios and Costell, 2004).

To increase the acceptability of soymilk beverages one must gain a better understanding of their chemical, physical and sensorial characteristics and how each of these influences the consumer's final response.

The objectives of this work were: 1) to analyse the differences in acceptability between commercial vanilla-flavoured milk and soymilk beverages; 2) to study how acceptability is influenced by demographic characteristics, consumer habits and individual preferences; 3) to analyse the relationship between acceptability and the sensorial differences perceived between samples. 


\section{$<$ 1>MATERIALS AND METHODS}

\section{$<2>$ Samples}

Six commercial samples, comprising three vanilla milk beverages and three vanilla soymilk beverages, of different brands and characteristics were selected (Table 1). The selection criteria were based on preliminary experiences analysing the instrumental colour and viscosity ranges of different commercial samples and on the identification of leading market brands. The samples were purchased from the local supermarket taking into account expiration dates (the same for each brand) and were stored at $4 \pm 1{ }^{\circ} \mathrm{C}$ prior to testing. All measurements were performed within the declared shelf-life period of each sample more than two months before expiration date.

\section{$<2>$ Methods}

\section{$<3>$ Soluble Solids and $\mathrm{pH}$}

Soluble solids were determined in a digital refractometer ATAGO RX-100 (Atago Co. Ltd. Tokio, Japan) at room temperature and the results expressed as degrees Brix at $20{ }^{\circ} \mathrm{C}$. A digital $\mathrm{pH}$ meter GLP 21 (Crison Instruments SA. Barcelona, Spain) was used to measure pH at room temperature. Both measurements were taken in duplicate for each sample.

\section{$<3>$ Sensory Evaluation}

Two sensory methods were applied: a consumer acceptability test and a ranking test (ISO, 2006). It was previously confirmed that both consumers and assessors had no allergies to milk or soy. Overall acceptability was tested by 142 Spanish consumers, using a 9-point hedonic scale ranging from 1 ("dislike extremely") to 9 ("like extremely"). The participants were selected according to the following criteria: age, gender and habitual consumers of milk and/or vegetable beverages, at least one time at week. Consumers were recruited by a local consumer association (AVACU) through a short questionnaire sent by mail. Some demographic and sociological characteristics of consumers are shown in Table 2. They were given a brief overview of how the sensory test would be conducted and they filled in a brief questionnaire about their knowledge and consumer habits with respect to milk and vegetable beverages. Each consumer evaluated the six samples in one session. The order of sample presentation was fixed across consumers according to a Williams design for six samples in balanced blocks of six consumers (MacFie et al., 1989). To eliminate the first position bias, a seventh vanilla beverage sample, the same for each consumer, was evaluated first for all the serving orders as a dummy sample (Lange et al., 1999). The samples $\left(30 \mathrm{~mL}\right.$ ) were served at $10 \pm 1{ }^{\circ} \mathrm{C}$, in white plastic cups codified with three-digit random numbers and were presented monadically for overall acceptability evaluation.

Differences in perception of yellow colour, brightness, vanilla flavour intensity, sweetness and thickness among the six samples evaluated (three vanilla milk beverages and three vanilla soymilk 
beverages) were analysed using a ranking test (ISO, 2006; Meilgaard et al., 1999) by thirty-six assessors, with previous experience (more than four years) in evaluating sensory differences in dairy products using discriminant or ranking tests. The assessors were previously selected according to their taste sensitivity and their capacity to detect differences in intensities of the above mentioned attributes (ISO, 1993). First, they ranked the six samples from the least to the most intense according to their yellow colour and to their brightness by observing the samples in a colour viewing chamber equipped with illuminant D65 (ICS-Texicon España SA. Barcelona, Spain). Light from this source was projected vertically onto the sample and observed at an angle of $45^{\circ}$ (ISO, 1999). Secondly, the assessors ranked the samples from the least to the most intense according to their vanilla flavour intensity, sweetness and thickness in separate booths in a standardized test room (ISO, 1988). As in the acceptability evaluation, the samples were served at $10 \pm 1{ }^{\circ} \mathrm{C}$, in white plastic cups codified with three-digit random numbers although in this case they were presented simultaneously to the assessors.

In both types of test, mineral water was provided for mouth-rinsing. Sessions were carried out before lunch time (11.00 - 13.00). Data acquisition was performed using Compusense ${ }^{\circledR}$ release 4.6 software (Compusense Inc., Guelph, Ontario, Canada).

\section{$<3>$ Statistical Analysis}

Two-way analysis of variance (ANOVA) with sample and consumer being sources of variation, was applied to the overall acceptability data. Significance of differences between samples was determined by Fisher test $(\alpha \leq 0.05)$ using XLSTAT-Pro software v. 2007 (Addinsoft, France). The Taguchi's signal-to-noise ratio (SNR) (Equation 1) was calculated in order to know the robustness of acceptability mean values of samples (Gacula, 1993; Gacula et al., 2007; Pastor et al., 1996),

$\mathrm{SNR}=-10 \log \left[(1 / \bar{y})\left(3 s^{2} / \bar{y}^{2}\right)\right]$

where $\bar{y}$ and $s^{2}$ are sample mean and sample variance, respectively.

To study the influence of gender, age and soymilk consumption on the acceptability data, three independent two-way analyses of variance with interaction were applied, with sample as source of variation in all of them.

Minimum significant differences were calculated by Fisher's LSD $(\alpha \leq 0.05)$ XLSTAT-Pro software.

Internal preference map was obtained for the overall acceptability data matrix using Senstools v. 3.3.2 (OP and P and Talcott, Utrecht, The Netherlands).

Friedman analysis of variance was applied to the sensory data obtained in the ranking tests, significance of differences between samples were determined by the Fisher test $(\alpha \leq 0.05)$ using Compusense software. Kendall's concordance coefficient (Equation 2) was calculated (Moskowitz, 1983 ) in order to measure how well the group, in general, agreed with the final ranking: 
$\mathrm{W}=\frac{12 S}{K^{2}\left(N^{3}-N\right)}$

where $S$ is the sum of squares of the observed deviations from the mean of the ranked totals, $K$ is the number of assessors and $N$ the number of samples ranked.

Principal Component Analysis (PCA) with varimax rotation was applied to the correlation matrix of the ranking sum values of sensory attributes using XLSTAT-Pro software.

In order to study the relationship between acceptability and sensory data, regression analyses were carried out between the values of the rank sum of each sensorial attribute and the coordinates of the samples in the first two dimensions of the internal preference map. Regression coefficients were calculated by using the PROFIT program of the PC-MDS Multidimensional Statistic Package v 5.1 software (Smith, 1990).

\section{$<1>$ RESULTS AND DISCUSSION}

$<2>$ Overall Acceptability

The surveyed consumers knew more about the milk beverages than the vegetable milks (Figure 1). Among the vegetable beverages included in the survey, the best known was soymilk at $94.4 \%$ followed by almond milk, while only $26.8 \%$ of the consumers stated that they had heard of rice milk and an even smaller percentage (17.6\%) of hazelnut milk. With respect to the consumption of each of these products in the previous month, semi-skimmed milk registered the highest consumption, followed by whole and skimmed milk (Figure 1). Chocolate milkshake consumption was intermediate between whole milk and skimmed milk. The vegetable beverage with highest consumption was soymilk, although the corresponding percentage was $14 \%$, clearly much lower than the milk beverages.

The results obtained were subjected to analysis of variance which revealed significant differences in the acceptability of the different samples $(\mathrm{F}=133.99, \mathrm{P}<0.0001)$. The milk samples were significantly more acceptable than the soymilk samples (Table 3), with acceptability values greater than 6 ("like slightly") compared to those below 4 ("dislike slightly") corresponding to the soymilk beverages. Evaluating a product degree of acceptability by just considering the average values obtained from the individual consumer's assessment, can lead to erroneous conclusions (Pastor et al., 1996; Carbonell et al., 2008) Often, this average value does not give information about the real acceptability of the product; rather it is the result of considering a series of opinions together that are more or less divergent. The lower the variability of the individual data, the better the mean value of the population represents the degree of real acceptability of the sample. The calculation of the Taguchi SNR index (signal-to-noise ratio) enables complementary information to be obtained regarding the robustness of the mean value of acceptability of each sample. For instance, in this case, the result of the ANOVA (Table 3) indicated that the samples M1 and M3 were equally acceptable. The almost identical values of the SNR index for these samples (15.7 and 15.8, respectively) indicated that the 
variability of the individual data of acceptability was also similar for both samples. However, although significant differences in acceptability were not detected between samples S1 and S3, the SNR index values (6.2 and 7.4, respectively) made apparent the lower extent of coincidence between the individual data for acceptability of sample S1 as compared to that recorded for sample S3. Even with this complementary information, the mean acceptability values do not always accurately reflect the opinion of the population surveyed because, frequently, not all the consumers have homogeneous acceptability criteria. Analysing the opinion of the different groups of consumers based on demographic criteria, in terms of their consumer habits or according to individual preferences, can afford more complete information about the real acceptability of the products under evaluation.

\section{$<2>$ Influence of Demographic Characteristics, Consumer Habits and Individual Preferences on Acceptability}

The differences between men and women with respect to sample acceptability were not significant ( $\mathrm{P}=0.053$, Table 4) although, in general, the men scored higher than women. Only one of the soymilk beverages (sample S2) was significantly more acceptable $(\alpha=0.05)$ for men than for women (Table 5). As far as age was concerned, a significant effect was detected in the interaction between this factor and the samples in terms of acceptability. This showed that differences did exist in the acceptability criteria of consumers of different ages (Table 4). Although the milk samples were significantly more acceptable than the soymilk samples for the whole population under survey, the greatest differences in acceptability were detected between extreme age groups. The youngest consumers (18-30 years) considered the milk sample M3 to be more acceptable and the soymilk beverages S2 and S3 less acceptable than the older consumers (Table 5).

On analysing the differences in sample acceptability between the consumers and nonconsumers of soymilk, a significant effect was found in the interaction between this consumer habit and sample acceptability (Table 4). However, differences were not detected in the acceptability of the milk samples between consumers and non-consumers of soymilk. The soymilk consumers awarded significantly higher acceptability values to this type of beverage, and even found one of the soymilk samples (S2) as acceptable as milk sample M2 (Table 5). This would seem to confirm that habitual consumption of a food increases its acceptability. To this effect, Luckow et al. (2005) observed a significant increase in the acceptability of a series of probiotic beverages after they had been consumed daily for a week, and Stein et al. (2003) found a positive correlation between familiarity and the level of liking in a study on the acceptance of bitter beverages.

To obtain information about individual consumer preference, as well as to identify consumer groups with different preference patterns, the matrix of individual acceptability scores across the six samples was analysed by internal preference mapping. The amount of variance explained by the first two dimensions was $74 \%$ and the preference space defined by these dimensions is shown in Figure 2 . This space represents the consensus configuration of the six samples based on the overall acceptability 
data. Each point represents the end of each consumer's acceptance vector and each vector can be visualized by drawing a line from the centre to the point, the length of vectors indicating to what extent the variance of the consumers' individual acceptability scores is explained by the dimensions of the plot. Points showing the preference direction for each consumer were mainly concentrated in the region of positive scores in dimension 1. Consumer population was segmented by similarity of preference using the quadrants defined by the two dimensions (Greenhoff and MacFie, 1994; Damasio et al., 1999; Costell et al., 2000). Ninety-six percent (96\%) of consumers are located in the right-hand side of the map, constituting two subgroups in terms of their position in the upper part (subgroup I, $\mathrm{n}=$ 69 ) or at the bottom of the diagram (subgroup II, $n=67$ ). The difference between sample acceptability for both subgroups of consumers was not significant $(\mathrm{P}=0.057$, Table 4$)$. The consumers in subgroup I significantly assessed the soymilk beverages as more acceptable than those in subgroup II (Table 5) although, the acceptability of these beverages did not obtain a 5-point qualification in any case ("neither like nor dislike") while the acceptability of the milk beverages oscillated between 6 and 6.7 ("like slightly").

\section{$<2>$ Relationship between Acceptability and the Sensorial Differences among Samples}

The Friedman analysis of variance of the results of the ranking tests indicated that there were significant differences between samples for all the attributes evaluated (Table 6). The milk samples were perceived as being more intense and less light in colour, with a stronger vanilla flavour and more intense sweetness and thicker consistency (Table 7).

According to the values of the Kendall concordance coefficient (Table 6), the tasters displayed good concordance in their assessment of the perceptible differences between samples, except for thickness, for which the coefficient was somewhat lower.

A Principal Component Analysis was applied to the values of the rank sums of the assessed attributes. The three first components explained $99.3 \%$ of the variance (Figure 3 ). The first component was mainly associated to colour $(r=0.89)$ and thickness $(r=0.76)$, separating the samples M1 and M3 on the right-hand side of the plot, because they are the yellowest and most viscous samples. The second component was strongly associated to the light colour of the samples $(r=0.94)$, separating sample M2 from the rest, for being the darkest of all. The third component clearly separated sample S2 from the other soymilk samples. This component was fundamentally associated to flavour aspects. According to its position on the plot, sample S2 (Table 7) was the most similar in terms of vanilla flavour and sweetness intensity to the milk samples (M1, M2 and M3). This coincides with the value obtained for the measurement of soluble solids ( ${ }^{\circ}$ Brix) of sample S2 $(18.3 \%)$, which was higher than that of the other soymilk samples and similar to samples M1 and M3 (Table 1).

On studying the relationship between the main dimensions of the internal preference map (Figure 2) and the difference in intensity of the sensorial traits analysed (Table 7), one can observe that the milk samples were a stronger yellow in colour, with a stronger vanilla flavour, sweeter and more 
viscous than the soymilk beverages (Figure 4). The fact that one of the soymilk samples (S2) was more acceptable than the other two (Table 3), could be related to its more intense vanilla flavour and sweetness (Table 7). These results coincide with those obtained by Wang et al. (2001), who observed that sweeteners were necessary to enhance palatability and that the addition of different flavouring agents slightly improved the acceptance of soymilk beverages.

\section{$<1>$ CONCLUSIONS}

The results obtained led us to conclude that there is a significant difference between the acceptability of the vanilla-flavoured milk and that of soymilk beverages. Moreover, they indicated that this difference was more closely related to the sensorial aspects of both types of beverages than to other characteristics (demographic, consumer habits and individual preferences) of the consumer population surveyed.

The results also indicated that, despite the problems related to its particular flavour, it would be possible to improve the acceptability of the vanilla-flavoured soymilk beverages by modifying their formulation to obtain sweeter and more viscous products, with a stronger vanilla flavour. It is necessary to carry out a more in-depth study of the concentration of each ingredient needed to modify the sensory perceived colour, flavour and viscosity of these products, without forgetting to analyse the possible effect that interactions between the different ingredients can have on the sensorial quality of the final product.

\section{$<$ 1>ACKNOWLEDGMENTS}

To MEC of Spain for financial support (Projects AGL 2006-04027 and AGL2007-63444) and for the fellowship awarded to author B.Villegas

\section{$<1>$ REFERENCES}

Barrios E.X. and Costell E. (2004). Use of Methods of Research into Consumers' Opinions and Attitudes in Food Research. Food Science and Technology International 10: 359-371.

Carbonell L., Izquierdo L., Carbonell I. and Costell E. (2008). Segmentation of food consumers according to their correlations with sensory attributes projected on preference spaces. Food Quality and Preference 19: 71-78.

Chambers E., Jenkins A. and McGuire B.H. (2006). Flavor properties of plain soymilk. Journal of Sensory Studies 21: 165-79. 
Costell E., Pastor M.V., Izquierdo L. and Duran L. (2000). Relationships between acceptability and sensory attributes of peach nectars using internal preference mapping. European Food Research and Technology 211: 199-204.

Damasio M.H., Costell E. and Duran L. (1999). Optimising acceptability of low-sugar strawberry gels segmenting consumers by internal preference mapping. Journal of the Science of Food and Agriculture 79: 626-32.

Deshpande R.P., Chinnan M.S. and McWatters K.H. (2005). Nutritional, physical and sensory characteristics of various chocolate-flavored peanut-soy beverage formulations. Journal of Sensory Studies 20: 130-46.

Gacula M.C. (1993). Design and Analysis of Sensory Optimization. Connecticut: Food \& Nutrition Press, Inc. pp 301.

Gacula M.C., Rutenbeck S., Pollack L., Resurrección A.V.A. and Moskowitz H.R. (2007). The justabout-right intensity scale: functional analyses and relation to hedonics. Journal of Sensory Studies 22: 194-211.

Greenhoff K. and MacFie H.J.H. (1994). Preference mapping in practice. In: MacFie H.J.H. and Thomson D.M.H. (eds), Measurement of food preferences. Glasgow: Blackie Academic and Professional (Chapman\&Hall). pp.137-166.

Hasler C.M. (1998). Functional foods: Their role in disease prevention and health promotion. Food Technology 52: 63-70.

Hayta M., Alpaslan M. and Cakmakli U. (2003). Physicochemical and sensory properties of soymilkincorporated bulgur. Journal of Food Science 68: 2800-2803.

ISO (1988). General guidance for the design of test room. Standard No 8589. International Organization for Standarization, Geneva, Switzerland.

ISO (1993). Sensory analysis. General guidance for the selection, training and monitoring of assessors. Part 1: Selected assessors. Standard No. 8586-1. International Organization for Standarization, Geneva, Switzerland.

ISO (1999). General guidance and test method for the assessment of the colour of foods. Standard No 11037. International Organization for Standarization, Geneva, Switzerland.

ISO (2006). Sensory analysis. Methodology. Ranking. Standard No 8587. International Organization for Standarization Geneva, Switzerland.

Keast R.S.J. and Lau J.J. (2006). Culture-specific variation in the flavor profile of soymilks. Journal of Food Science 71: S567-S572. 
Lange C., Rousseau F. and Issanchou S. (1999). Expectation, liking and purchase behaviour under economical constraint. Food Quality and Preference 10: 31-39.

Luckow T., Sheehan V., Delahunty C. and Fitzgerald G. (2005). Determining the odor and flavor characteristics of probiotic, health-promoting ingredients and the effects of repeated exposure on consumer acceptance. Journal of Food Science 70: S53-S59.

MacFie H.J., Bratchell N., Greenhoff K. and Vallis L.V. (1989). Designs to balance the effect of order of presentation and first-order carry-over effects in hall test. Journal of Sensory Studies 4: 129-148.

Meilgaard M., Civille G.V. and Carr B.T. (1999). Sensory Evaluation Techniques. 3rd edn., Boca Raton: CRC Press, pp. 387.

Mepba H.D., Achinewhul S.C. and Pillay M. (2006). Stabilised cocosoy beverage: physicochemical and sensory properties. Journal of the Science of Food and Agriculture 86: 1839-1846.

Moskowitz H.R. (1983). Product Testing and Sensory Evaluation of Foods. Marketing and R\&D Approaches. Connecticut: Food \& Nutrition Press, Inc. pp. 605.

N'Kouka K.D., Klein B.P. and Lee S.Y. (2004). Developing a lexicon for descriptive analysis of soymilks. Journal of Food Science 69: S259-S263.

Pastor M.V., Costell E., Izquierdo L. and Durán L. (1996). Optimizing acceptability of a high fruitlow sugar peach nectar using aspartame and guar gum. Journal of Food Science 61: 852-855.

Potter R.M., Dougherty M.P., Halteman W.A and Camire M.E. (2007). Characteristics of wild blueberry-soy beverages. LWT-Food Science and Technology 40: 807-814.

Reilly J.K., Lanou A.J., Barnard N.D., Seidl K. and Green A.A. (2006). Acceptability of soymilk as a calcium-rich beverage in elementary school children. Journal of the American Medical Association 106: $590-593$.

Smith S.M. (1990). PC-MDS Multidimensional Statistic Package. Version 5.1. Institute of Business MGT, Brigham Young University, Provo, Utah.

Stein L.J., Nagai H., Nakagawa M. and Beauchamp G.K. (2003). Effects of repeated exposure and health-related information on hedonic evaluation and acceptance of a bitter beverage. Appetite $\mathbf{4 0}$ : 119-29.

Torres-Peñaranda A.V. and Reitmeier C.A. (2001). Sensory descriptive analysis of soymilk. Journal of Food Science 66: 352-56.

Wang B., Xiong Y.L. and Wang C. (2001). Physicochemical and sensory characteristics of flavoured soymilk during refrigeration storage. Journal of Food Quality 24: 513-526. 
Wang W.Y. and de Mejía E.G. (2005). A new frontier in soy bioactive peptides that may prevent agerelated chronic diseases. Comprehensive Reviews in Food Science and Food Safety 4: 63-78.

Yuan S.H. and Chang S.K.C. (2007). Selected odor compounds in soymilk as affected by chemical composition and lipoxygenases in five soybean materials. Journal of Agricultural and Food Chemistry 55: 426-431. 
Table 1. Ingredients and main characteristics of commercial milk and soymilk vanilla beverages samples.

\begin{tabular}{clcccc}
\hline Sample $^{1}$ & Main ingredients & Hydrocolloid ${ }^{2}$ & $\begin{array}{c}\text { Dietary } \\
\text { fiber }^{2} \\
(\mathrm{~g} / 100 \mathrm{~g})\end{array}$ & $\begin{array}{c}\text { Soluble } \\
\text { solids }^{3} \\
\left({ }^{\circ} \mathrm{Brix}\right)\end{array}$ & $\mathrm{pH}^{3}$ \\
\hline M1 & Skimmed milk & $\begin{array}{c}\text { Carrageenan, Guar- } \\
\text { gum }\end{array}$ & - & $17.0(0.07)$ & $6.68(0.06)$ \\
M2 & $\begin{array}{l}\text { Skimmed milk } \\
\text { Dairy solids }\end{array}$ & - & - & $14.7(0.11)$ & $6.82(0.13)$ \\
M3 & $\begin{array}{l}\text { Semi-skimmed milk } \\
\text { Dairy solids }\end{array}$ & Carrageenan & - & $18.4(0.11)$ & $6.82(0.02)$ \\
S1 & Soybean & - & 1.2 & $15.8(0.04)$ & $6.76(0.13)$ \\
S2 & Soybean & - & 0.6 & $18.3(0.04)$ & $7.64(0.03)$ \\
S3 & Soybean & - & 2.0 & $10.5(0.06)$ & $6.99(0.05)$ \\
\hline
\end{tabular}

${ }^{1}$ Milk beverages: M1, M2 and M3. Soymilk beverages: S1; S2 and S3.

${ }^{2}$ Declared in label.

${ }^{3}$ Average value of two samples. Standard deviations within parenthesis. 
Table 2. Demographic and sociological characteristics of consumers $(n=142)$.

\begin{tabular}{llcc}
\hline Characteristics & Category & $\begin{array}{c}\text { Number of } \\
\text { consumers }\end{array}$ & $\begin{array}{c}\text { Percentage } \\
(\%)\end{array}$ \\
\hline Gender & Women & 87 & 61.2 \\
Age group & Men & 55 & 38.8 \\
& $18-30$ & 80 & 56.3 \\
& $31-45$ & 36 & 25.4 \\
Marital status & $>45$ & 26 & 18.3 \\
& Single & 90 & 63.4 \\
& Married & 46 & 32.4 \\
& Others & 6 & 4.2 \\
Eccupation & Employee & 84 & 59.2 \\
& Student & 50 & 35.2 \\
& Housewife & 3 & 2.1 \\
& Unemployed & 5 & 3.5 \\
& Primary studies & 8 & 5.6 \\
& High school certificate & 37 & 26.1 \\
& Senior technician & 16 & 11.3 \\
& University degree & 81 & 57.0 \\
\hline
\end{tabular}


Table 3. Overall acceptability mean values $(n=142)$ and signal-to-noise ratio $(\mathrm{SNR})$ values of milk and soymilk vanilla beverages.

\begin{tabular}{lcccccc}
\hline & \multicolumn{6}{c}{ Sample $^{1}$} \\
\cline { 2 - 7 } & M1 & M2 & M3 & S1 & S2 & S3 \\
\hline Overall acceptability $^{2}$ & $6.6 \mathrm{a}$ & $6.1 \mathrm{~b}$ & $6.7 \mathrm{a}$ & $3.1 \mathrm{~d}$ & $4.0 \mathrm{c}$ & $3.4 \mathrm{~d}$ \\
SNR & 15.7 & 14.8 & 15.8 & 6.2 & 9.4 & 7.4 \\
\hline
\end{tabular}

${ }^{1}$ Identification of samples in Table 1.

${ }^{2}$ Values from 1 "dislike extremely" to 9 "like extremely". Values with different letters are significantly different (ANOVA, $\alpha=0.05$ ). 
Table 4. Two way analyses of variance with interactions for overall acceptability data.

\begin{tabular}{llcc}
\hline Factors & Source & F-ratio & P-value \\
\hline Gender and sample & Gender & 3.77 & 0.053 \\
& Sample & 107.08 & $<0.0001$ \\
& Gender*sample & 1.23 & 0.292 \\
Age and sample & Age & 0.51 & 0.602 \\
& Sample & 79.79 & $<0.0001$ \\
Consumption of soymilk and & Age*sample & 2.45 & 0.007 \\
sample & Consumption & 6.00 & 0.014 \\
\multirow{2}{*}{ Subgroup of consumer ${ }^{1}$ and } & Sample & 40.21 & $<0.0001$ \\
sample & Consumption*sample & 3.59 & 0.003 \\
& Subgroup of consumer & 3.63 & 0.057 \\
& Sample & 105.70 & $<0.0001$ \\
\hline
\end{tabular}

${ }^{1}$ From internal preference map. 
Table 5. Influence of different factors (gender, age, soymilk consumption and preference) on acceptability of milk and soymilk vanilla beverages.

\begin{tabular}{|c|c|c|c|c|c|c|c|c|c|}
\hline \multirow{3}{*}{ Sample $^{2}$} & \multicolumn{9}{|c|}{ Acceptability $^{1}$} \\
\hline & \multicolumn{2}{|c|}{ Gender } & \multicolumn{3}{|c|}{ Age } & \multicolumn{2}{|c|}{ Soymilk consumption } & \multicolumn{2}{|c|}{ Preference map } \\
\hline & Women & Men & $\begin{array}{c}\mathrm{G} 1 \\
(18-30)\end{array}$ & $\begin{array}{c}\mathrm{G} 2 \\
(31-45)\end{array}$ & $\begin{array}{c}\text { G3 } \\
(>45)\end{array}$ & $\begin{array}{c}\text { No } \\
\text { consumers }\end{array}$ & Consumers & $\begin{array}{c}\text { Subgroup } \\
\text { I }\end{array}$ & $\begin{array}{c}\text { Subgroup } \\
\text { II }\end{array}$ \\
\hline M1 & $6.5 \mathrm{abc}$ & $6.9 \mathrm{a}$ & $6.9 \mathrm{a}$ & $6.4 \mathrm{ab}$ & $6.3 \mathrm{ab}$ & $6.6 \mathrm{ab}$ & $6.5 \mathrm{abc}$ & $6.7 \mathrm{a}$ & $6.5 \mathrm{ab}$ \\
\hline M2 & $6.3 \mathrm{bc}$ & $6.0 \mathrm{c}$ & $6.2 \mathrm{~b}$ & $6.0 \mathrm{~b}$ & $6.1 \mathrm{~b}$ & $6.2 \mathrm{bc}$ & $5.6 \mathrm{~cd}$ & $6.0 \mathrm{~b}$ & $6.3 \mathrm{ab}$ \\
\hline M3 & $6.6 \mathrm{abc}$ & $6.9 \mathrm{ab}$ & $7.1 \mathrm{a}$ & $6.4 \mathrm{ab}$ & $6.0 \mathrm{~b}$ & $6.7 \mathrm{a}$ & $6.5 \mathrm{abc}$ & $6.6 \mathrm{ab}$ & $6.7 \mathrm{a}$ \\
\hline $\mathrm{S} 1$ & $3.0 \mathrm{f}$ & $3.3 \mathrm{ef}$ & $3.2 \mathrm{ef}$ & $2.8 \mathrm{f}$ & $3.4 \mathrm{def}$ & $3.0 \mathrm{~h}$ & $4.0 \mathrm{fg}$ & $3.5 \mathrm{~d}$ & $2.7 \mathrm{e}$ \\
\hline $\mathrm{S} 2$ & $3.7 \mathrm{e}$ & $4.5 \mathrm{~d}$ & $3.6 \mathrm{de}$ & $4.5 \mathrm{c}$ & $4.5 \mathrm{c}$ & $3.8 \mathrm{fg}$ & $5.3 \mathrm{de}$ & $4.3 \mathrm{c}$ & $3.7 \mathrm{~d}$ \\
\hline S3 & $3.4 \mathrm{ef}$ & $3.4 \mathrm{ef}$ & $3.2 \mathrm{ef}$ & $3.3 \mathrm{def}$ & $4.1 \mathrm{~cd}$ & $3.2 \mathrm{gh}$ & $4.3 \mathrm{ef}$ & $3.4 \mathrm{~d}$ & $3.3 \mathrm{de}$ \\
\hline
\end{tabular}

${ }^{1}$ Values from 1 "dislike extremely" to 9 "like extremely". Values within a column and/or a row for the same factor with different letters from each one of the ANOVAs are significantly different $(\alpha=0.05)$.

${ }^{2}$ Identification of samples in Table 1. 
Table 6. Friedman value and Kendall's concordance coefficient for the sensory attributes evaluated by ranking test.

\begin{tabular}{lcc}
\hline Sensory attribute & $\begin{array}{c}\text { Friedman value }^{1} \\
\text { (F) }\end{array}$ & $\begin{array}{c}\text { Kendall's coefficient } \\
\text { (W) }\end{array}$ \\
\hline Colour & 135.34 & 0.75 \\
Darkness & 129.22 & 0.72 \\
Vanilla & 121.44 & 0.67 \\
Sweetness & 132.01 & 0.73 \\
Thickness & 76.34 & 0.42 \\
\hline
\end{tabular}

${ }^{1}$ Theoretical $\mathrm{F}$ value being 11.07 for $\alpha=0.05$. 
Table 7. Total rank sum for the different sensory attributes for milk and soymilk vanilla beverages.

\begin{tabular}{cccccc}
\hline & \multicolumn{5}{c}{ Sensory attributes } \\
Sample & \multicolumn{5}{c}{} \\
\cline { 2 - 6 } & Color & Brightness & Vanilla flavor & Sweetness & Thickness \\
\hline M1 & $213 \mathrm{a}$ & $88 \mathrm{~d}$ & $184 \mathrm{a}$ & $180 \mathrm{a}$ & $174 \mathrm{a}$ \\
M2 & $121 \mathrm{c}$ & $43 \mathrm{e}$ & $163 \mathrm{a}$ & $138 \mathrm{~b}$ & $139 \mathrm{~b}$ \\
M3 & $181 \mathrm{~b}$ & $126 \mathrm{c}$ & $175 \mathrm{a}$ & $195 \mathrm{a}$ & $177 \mathrm{a}$ \\
S1 & $91 \mathrm{~cd}$ & $132 \mathrm{bc}$ & $76 \mathrm{bc}$ & $74 \mathrm{c}$ & $102 \mathrm{c}$ \\
S2 & $73 \mathrm{~d}$ & $158 \mathrm{~b}$ & $104 \mathrm{~b}$ & $121 \mathrm{~b}$ & $89 \mathrm{c}$ \\
S3 & $77 \mathrm{~d}$ & $209 \mathrm{a}$ & $54 \mathrm{c}$ & $48 \mathrm{c}$ & $75 \mathrm{c}$ \\
\hline
\end{tabular}

${ }^{1}$ Values within a column with different letters are significantly different $(\alpha=0.05)$.

${ }^{2}$ Identification of samples in Table 1. 


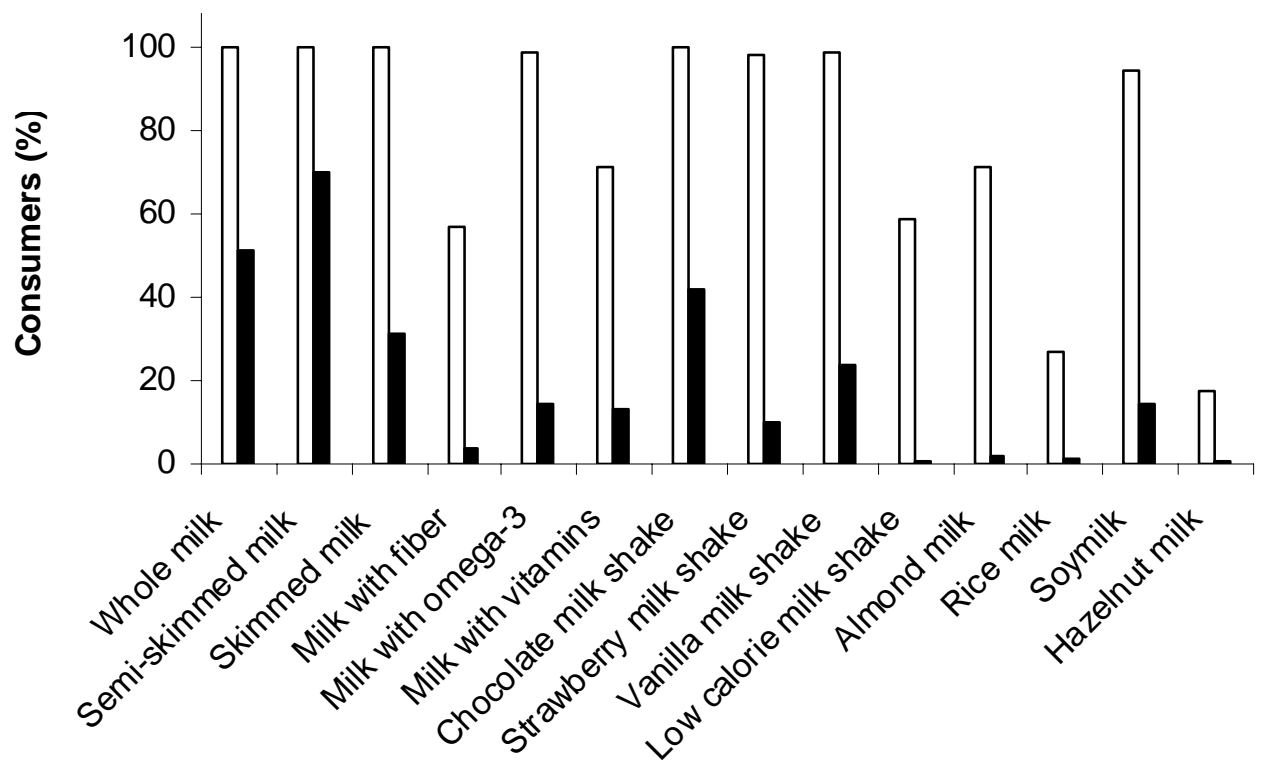

Figure 1. Knowledge ( $\square$ ) and last month consumption ( $\square$ ) of different milk and vegetable beverages to the surveyed population $(\mathrm{n}=142)$. 


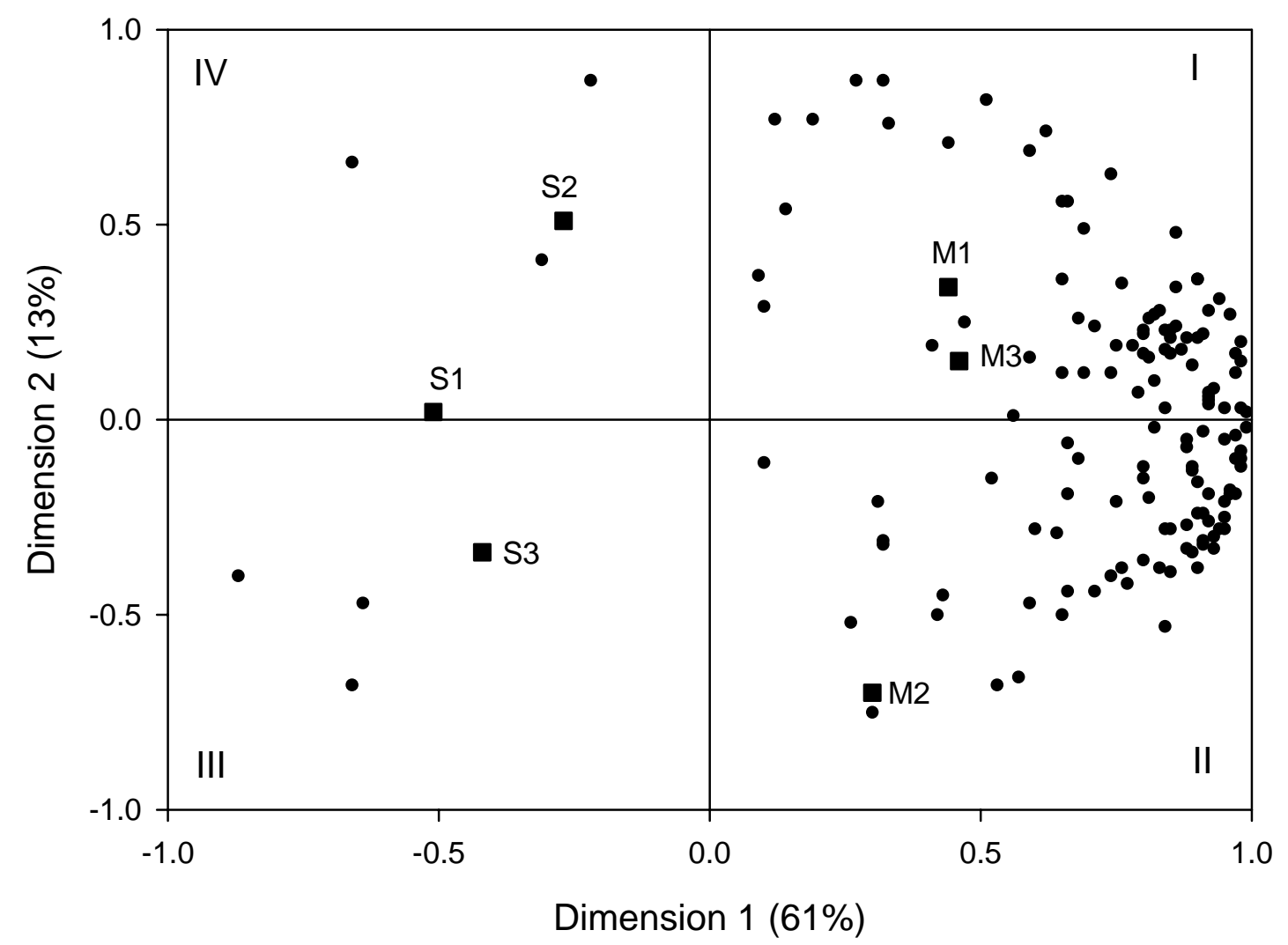

Figure 2. Internal preference map for overall acceptability of milk and soymilk vanilla beverages. Identification of samples in Table 1. 

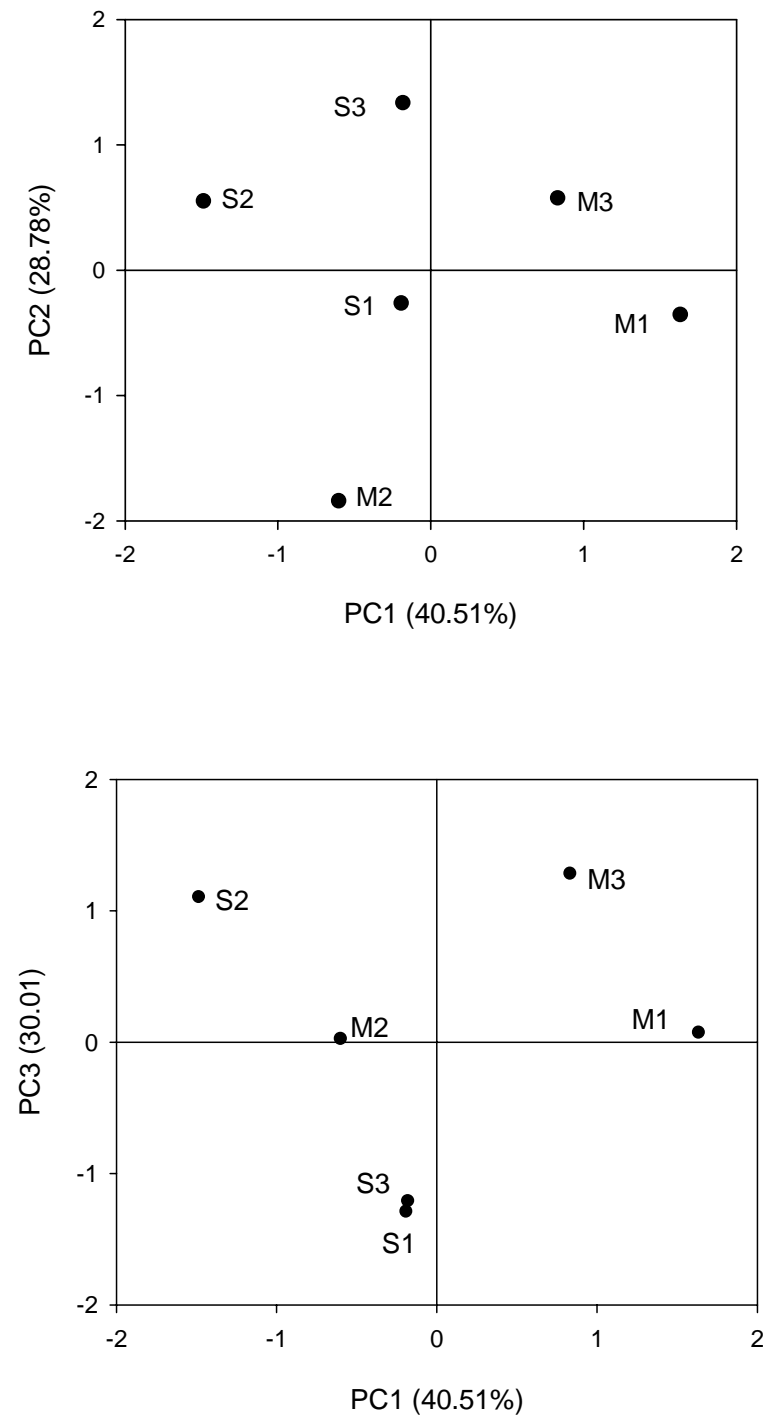

Figure 3. Principal component analysis biplot for milk and soymilk vanilla beverages. Identification of samples in Table 1. 


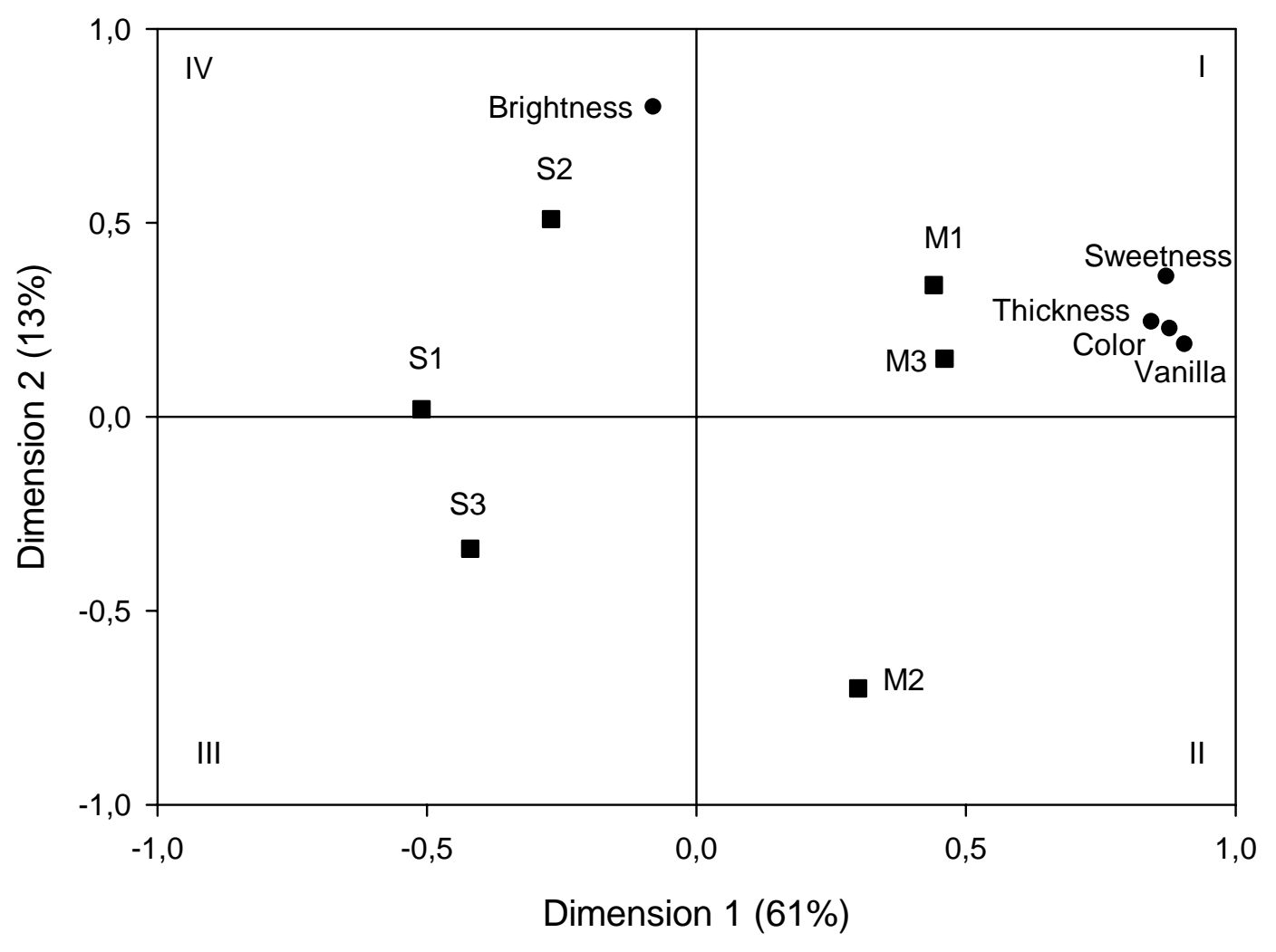

Figure 4. Consumer's preferences of milk and soymilk vanilla beverages in relation to sensory attributes. Identification of samples in Table 1. 